\title{
Training of health referents at child care centers. Experience in Argentina
}

\author{
M. Elina Serra ${ }^{(\mathbb{D}}$, Rose M. Soria $\mathbb{D}^{(\mathbb{D}}$
}

\begin{abstract}
An adequate child care helps to mitigate the effects of social adversity. Health prevention is a part of it. This is an innovative training program for health referents in child care centers that cater to vulnerable populations in Buenos Aires, Argentina.

It consisted in training child care center staff, followed by the implementation, over 4 months, of an improvement plan developed by each participant in their center, with ongoing advisory support. In total, 26 participants from 19 centers completed the program. In total, 35 out of 49 goals proposed in the plans were achieved, including the certification in cardiopulmonary resuscitation, staff and family training, development of center policies, and improved resource management.

Preventive care offered in child care centers may be improved via a simple and inexpensive intervention, including in unfavorableconditions. Key words: childhood, child care, kindergartens, health promotion, vulnerable populations.
\end{abstract}

http: / / dx.doi.org/10.5546/ aap.2022.eng.122

To cite: Serra ME, Soria RM. Training of health referents at child care centers. Experience in Argentina. Arch Argent Pediatr 2022;120(2):122-128.

\section{INTRODUCTION}

An adequate health status is critical for growth and development during early childhood. Social adversity has an impact on different biological systems that contribute to health deterioration and negative social outcomes throughout life..$^{1,2}$ Disease may limit not only learning and educational trajectories, but also well-being in the long term during adulthood. The evidence suggests that high-quality care, accompanied by preventive measures in a safe environment, is a cost-effective intervention to improve, and even revert, the consequences of unfavorable child experiences. ${ }^{3}$
In Argentina, more than 50\% of children are poor and $26 \%$ have limited or null access to health services. ${ }^{4}$ In these circumstances, attending a child care center may be considered a valuable opportunity for health care. ${ }^{5}$ However, the implementation of preventive measures in this setting is limited due to the absence of specific preventive health care guidelines developed for this field and the lack of staff training on this subject. Such deficiencies are not exclusive to Argentina, they are also common to many Latin American countries. ${ }^{6}$

Based on the preceding, our team developed an innovative onsite training program on preventive care targeted at the staff of child care centers that cater to socially vulnerable communities.

This article describes the experience, methodology, challenges, and results of this initiative, the first of this kind in Latin America.

\section{METHODS}

This is a free training program developed in the Metropolitan Area of Buenos Aires (AMBA), Argentina.

Participants were selected by interviews after an open invitation via social media (April-May 2019). Selection criteria were working at a center that catered to a socially vulnerable population and showing an evident interest in receiving training in child health care and a leadership profile.

The program started in June 2019 and included a training period with 3 full-time in-person meetings every 2 weeks followed by a period for the implementation of an improvement plan at each center for 4 months. The 
program was led by a pediatrician and a nurse experienced and trained in health advisory for child care centers.

During the first meeting, participants completed a baseline survey about preventive measures. Then, the general definitions about child health and the setting of the child care center were described. Participants received a manual for health practices in early childhood spaces, based on the available evidence and especially designed by our team for this training (available with free access at https: / / drive.google.com/ file/d/1TO otWje1OPoYWDXj417c32oqGDgvHqUr/view). Each participant received the copies they had requested for distribution in their place of work.

During the second meeting, the discussion focused on how to diagnose prevailing problems and establish priorities to develop an action plan for each center. An observation guideline and an interview (designed and administered by our team in advance) were offered as support. This guideline contains 62 critical items, including those related to institutional standards, information about critical procedures, minimal infrastructure, and staff knowledge about prevailing health problems. It is available online and with free access. ${ }^{7}$

For the following 2 weeks, participants observed situations and interviewed the centers' directors to make a diagnosis. Then, they selected 1 or several (maximum 4) problems that should be addressed through an improvement plan over 4 months.

A multiple choice assessment was provided at the beginning of the third meeting. A minimum of $18 / 25$ correct answers was required to pass it. The third meeting focused on discussing the outcomes of each diagnosis, sharing ideas, and adjusting preliminary improvement plans.

Participants were asked to submit their written plans, with details of each topic to improve, goals, and strategies to be implemented in the following 4 months. During the implementation period, a virtual classroom was available to exchange information among participants, communicate with trainers, and report on the progress in a regular manner. Such regular contact allowed to correct mistakes and adjust the plans as necessary.

After 4 months (November 2019), each participant developed a final report and was interviewed. The semi-structured interview (see Annex) was an opportunity to assess the strengths, challenges, and results obtained, and also to discuss the strategies to continue with each plan after the training period, ask if expectations were met, about the most relevant aspects of the training provided, and ask for suggestions to improve new editions.

A follow-up telephone interview was planned 6 months after the program ended to confirm whether planned strategies had been implemented in an ongoing basis. Due to the COVID-19 pandemic and the resulting closing of child care centers, this follow-up interview was modified. Instead of asking about previous plans, participants were asked about the tools learned during training that they considered most useful in such epidemiological situation and about the challenges they foresaw in relation to centers reopening.

Data analysis. Descriptive statistics were used to summarize the characteristics of participants, data about diagnosis at child care centers, and improvement plans.

Ethical aspects. This study describes a training experience and was not designed as a research project; therefore, the approval from an ethics committee was not deemed necessary. However, participants were asked to submit their own commitment letter and a commitment letter from the center's director and to provide their written consent for the publication of data regarding this experience.

\section{RESULTS}

Sixty-three candidates answered the invitation. After screening them, 30 participants from 23 centers were accepted to the program, including 3 government program coordinators, whose role was to manage several participating centers. The goal of their participation was to both offer support to their centers and receive training themselves. Four participants did not complete training due to personal reasons. In total, 26 participants ( 25 females and 1 male) from 19 centers completed the program: educational psychologists (7), teachers (7), social workers (6), psychologists (2), psychomotor specialist (1), nutritionist (1), nursery nurse (1), and education student (1). Their median age was 47 years (min.: 27-max.: 72). They had been working in the field of childhood for a median of 16 years (min.: 1.5max.: 35). Only 13 of these participants had been offered training in health prevention before, although such training focused on specific topics.

The centers whose participants completed the program received public funds $(n=6)$ or were non-governmental community centers $(n=13)$. 
At each center, the team was made up of at least 1 social worker, 1 psychologist, and 1 educational psychologist, and a variable number of care providers and / or teachers. The characteristics of each center are presented in Table 1.

The initial survey showed that, among the 30 initial participants, 15 correctly answered the questions about safe play; 17 , about child development and safe sleep; 24, about emergencies; 25, about injury prevention; and 27, about breastfeeding.

Following the first 2 training meetings, all participants analyzed $(n=26)$ passed the assessment. The number of correct answers ranged between 21 and 25 among a total of 25 .

The diagnosis of centers showed that, in 13 out of 19, no staff member had received training in cardiopulmonary resuscitation (CPR) and, in 6 out of 13 , no health promotion activity had been offered to staff or the community in the past year. Other conditions were detected that hurdle the implementation of preventive measures, such as inadequate infrastructure and lack of protocols (Table 2).

TABLE 1. Characteristics of the population attending participating centers

\begin{tabular}{lcc}
\hline Variable & Median & Min.-max. \\
\hline Children and adolescents (N) & 125 & $32-236$ \\
Children younger than 6 years (N) & 71 & $14-248$ \\
Care providers and/or teachers (N) & 12 & $3-20$ \\
Cleaning staff (N) & 2 & $1-4$ \\
Child-adult ratio & 10.4 & $6.25-51.6$ \\
\hline
\end{tabular}

$\mathrm{N}$ : number at each center.
Each participant developed an improvement plan with up to 4 goals (Table 3). A total of 49 goals related to different topics were established. The strategies proposed to reach such goals included on-site staff training and supervision (19); community activities for health promotion (9); the development of specific center protocols, e.g., hand hygiene, cleaning routine, safe sleep, etc. (16); resource management (12); signposting (emergency, hand washing) (8); and medical records and absenteeism records (3).

The 26 participants who passed the assessment completed a follow-up period of 4 months. In the setting of such improvement plans, they trained 237 care providers or teachers from the 19 centers in preventive health care measures.

Once the need was identified, our team offered a non-mandatory CPR session for participants and other staff members of participating centers. A total of 31 care providers from 7 participating centers were trained. In addition, 16 staff members from 1 center received on-site CPR training.

During the implementation of proposed improvement plans, 8 health promotion activities for communities were offered, 12 center-specific protocols were developed, resource management was optimized in 7 centers, registries were implemented in 3 centers, and emergency and hand washing signs were placed in 8 centers.

Out of the 49 goals proposed initially, 35 were achieved; 14 were ongoing in November 2019.

During the final interviews, 10 participants stated that the training program met their expectations, whereas 16 said it had exceeded them. The most relevant contributions from the

TABLE 2. Diagnosis of situation at each center in relation to health prevention

\begin{tabular}{lc}
\hline Variable & Centers $(\mathbf{n}=\mathbf{1 9 )}$ \\
\hline Available written standards about hand hygiene & 10 \\
Available written standards about center cleaning & 15 \\
Available written standards about adult immunization & 9 \\
Available breastfeeding room (separate from the kitchen or bathroom) & 8 \\
Fully-supplied diaper changing stations* & 2 \\
Common bathroom & $23(7-52)^{\star *}$ \\
Coordinator with knowledge about safe sleep measures & 14 \\
Available toys for children with small parts & 4 \\
Playground/outside space in poor conditions & 14 \\
Emergency exits indicated with signs and unobstructed & 13 \\
Readily available emergency protocol for all staff members & 5 \\
\hline
\end{tabular}

*The station was considered fully-supplied if it was close to a sink with running water, liquid soap, disposable gloves, and a waterproof surface and was in adequate conditions for diaper changing.

${ }^{* *}$ Median (min.-max.). 
programs, based on participants' feedback, are shown in Table 4.

The most common suggestion (16) made by participants for future program editions was the conduct of in-person meetings more often to share their experiences and report on the advances made at each center. When asked about the specific benefit obtained by each center due to their participation in the program, the most common answer (11) was staff awareness about preventive health issues. In relation to difficulties in improvement plan implementation, 20 participants mentioned the initial resistance by the remaining staff members.

Preventive health-related aspects planned for improvement in the following semester are shown in Table 5.

Follow-up telephone interviews were conducted with 18/19 participating centers. The answers obtained from these interviews showed that the training tools considered most useful were guidance for protocol development (9), greater knowledge about infectious disease dissemination (7), and a well-designed strategy for hand hygiene procedures (9). In relation to challenges, most participants pointed to the concern about social distancing during the pandemic because the general suggestions to organize activities and work in small groups to reduce virus dissemination (less hours of school and alternate schedules, among others) fail to consider the situation of socially vulnerable communities, in which parents depend on the child care center so that they can work (13). The lack of resources to maintain cleaning and disinfection routines was also a concern (4 answers).

\section{DISCUSSION}

According to the evidence, attending a child care center favors a better development, especially in vulnerable communities. ${ }^{8}$ However, to date, preventive health has not been considered a critical component of staff training working in the services of our region. This is the first experience of on-site training for staff working at child care centers in relation to preventive health in Argentina.

Child care centers in our region show a series of deficiencies, including dangerous facilities, lack of health prevention policies, shortage of qualified staff, and insufficient staff members to adequately care for children. ${ }^{9}$ These are all barriers for warranting a good quality of care. ${ }^{10}$ Financial support is required to overcome such deficiencies, which is an obstacle in developing countries, like Argentina. However, in this setting, training, which is based on strategies

TABle 3. Problems selected and included in improvement plans

\begin{tabular}{lc}
\hline Problem & Number of participants who selected it \\
\hline Hand hygiene & 15 \\
Diaper changing & 9 \\
Cleaning routine at the center & 6 \\
Emergency management & 5 \\
Safe sleep & 4 \\
Children health checkup records & 4 \\
Breastfeeding & 2 \\
Food safety & 1 \\
Electronic devices and poor screen use & 1 \\
Playground/outside space safety & 1 \\
First aid kit & 1 \\
\hline
\end{tabular}

TABLE 4. Most relevant characteristics and/or contributions resulting from the training program based on participants' feedback

\begin{tabular}{lc}
\hline Characteristic & Number of participants $(\mathbf{n}=\mathbf{2 6})$ \\
\hline Program usefulness / applicability & 9 \\
The program provided a new perspective about the child care center & 7 \\
Innovation & 4 \\
The manual for healthy care practices is evidence-based & 3 \\
The system to develop and address the improvement plan & 2 \\
The program's content is complete & 1 \\
\hline
\end{tabular}


proposed by health advisors and representatives and implemented in other regions, ${ }^{11,12}$ may be a relatively inexpensive investment to improve the conditions and services of child care centers.

The main strength of this experience includes learning about health prevention aspects and the achievement of most proposed goals based on each center's needs. As seen in other studies, training and ongoing guidance helped to develop policies and establish changes in the behavior of staff members and the center setting. ${ }^{13-17}$ In addition, participants deemed this experience an opportunity to work with children's families in health environments and improved healthrelated practices. Vulnerable communities have difficulties accessing the health care system and have less resources and information available than other groups in terms of health promotion. Health referents of child care centers may identify health needs and encourage healthy habits in an effective manner among community families. ${ }^{18-20}$

The aspects to be improved varied among centers. Most participants selected hand hygiene as a priority, which is consistent with the lack of a general regulation in relation to this aspect and its relevance for infection prevention. CPR training was also mentioned as a need, which is consistent with the lack of legal requirements for the training of child care center staff members. Some aspects, such as special care needs or gender identity or expression, indicate that diversity and inclusion are still challenges that have not been recognized in our setting.

Prior experiences focused on training staff in preventive health measures on-site at the centers, but failed to address policy development, coordination, and implementation of plans in the long term. ${ }^{21-27}$ Although these studies provided positive results, their impact was limited. Instead, this initiative emphasized the training of a staff member as health referent. Such referent not only acquires knowledge, but also has an opportunity to observe and develop organizational and implementation skills to adapt processes, facilitate behavioral change, and encourage an adequate setting for disease prevention measures. ${ }^{28,29}$ This type of training, whose objective is to train staff members to become health leaders in their centers, is innovative in our region. ${ }^{30}$

Unlike other experiences, ${ }^{27}$ in our case, participants continued in contact with advisors, who asked about new COVID-19-related measures and the plans to reopen the centers once the project had ended.

The data obtained from this experience showed that certain health care conditions cannot be easily changed (e.g., the main infrastructure problems), but other variables, including staff training, community health promotion, and organizational policies, may be reviewed in depth and improved by means of this training.

A limitation of this initiative is the small sample size, which is intrinsic to this type of educational intervention. Given its design, this training is offered to a limited number of participants at a time. Therefore, each participant is accompanied by the advisor throughout the training. This is part of the training strategy and helps participants to feel comfortable to promote collaboration and a smooth idea exchange. ${ }^{31}$

Unlike other interventions, in the case of this training, it is not possible to plan every detail in advance; it is necessary to make adjustments and encourage participants with every challenge faced by them. ${ }^{32}$

Another limitation of this experience is the variability in how each center works (based on heterogeneity in terms of infrastructure, human resources, and dependence in each center), which hurdles the generalization of results. Lastly, the fact that only progress indicators can be identified instead of measurable health outcomes may be considered a weakness.

This project focused on improving health care

TABLE 5. Health prevention problems planned for improvement during the following semester

\begin{tabular}{lc}
\hline Selected problem & Number of centers \\
\hline Cleaning routine at the center & 8 \\
Community activities for health promotion & 5 \\
Introduction of content about child health in the center's institutional project & 6 \\
Diaper changing protocol & 3 \\
Breastfeeding & 3 \\
Toy cleaning protocol & 2 \\
Hand hygiene & 1 \\
Unintentional injury prevention & 1 \\
\hline
\end{tabular}


conditions that may be modified, even in settings with many deficiencies, as the ones observed in Latin America. This project is innovative in our region because of the approach selected for the intervention, which entails strengthening the role of the child care center by turning it into a referral for health protection and promotion among the families sharing the community. Assistance programs are usually a more traditional strategy for these interventions, and so they have a limited impact and are unsustainable over time. Instead, this project proposes to train staff members for the effective self-management of any necessary resources for the exercise of the right to health during childhood, because it allows to adapt optimal measures to the reality of each center and favors the ownership of the improvement process by staff members. These results are surely maximized in relation to their effectiveness in the postpandemic context given the increase in poverty and the limited access to traditional health care.

\section{CONCLUSION}

The dissemination of this initiative may help to evidence the gap between theoretical definitions about children's rights and their effective implementation. In addition, it enlivens the discussion about the topics that have to be addressed in the setting of child care, together with the available strategies to overcome these challenges in Latin America.

\section{REFERENCES}

1. Berens AE, Jensen SKG, Nelson CA 3rd. Biological embedding of childhood adversity: from physiological mechanisms to clinical implications. BMC Med. 2017; 15(1):135.

2. Jensen SKG, Berens AE, Nelson CA 3rd. Effects of poverty on interacting biological systems underlying child development. Lancet Child Adolesc Health. 2017; 1(3):225-39.

3. Britto PR, Lye SJ, Proulx K, Yousafzai AK, et al. Nurturing care: promoting early childhood development. Lancet. 2017; 389(10064):91-102.

4. Tuñón I. Condiciones de vida de las infancias prepandemia COVID-19. Evolución de las privaciones de derechos 2010-2019. Documento estadístico. Serie Agenda para la Equidad (2017-2025). Buenos Aires; Barómetro de la Deuda Social Argentina; 2020. [Accessed on: July $\left.20^{\text {th }}, 2021\right]$. Available at: http://wadmin.uca.edu.ar/ public/ckeditor/Observatorio\%20Deuda\%20Social / Documentos / 2020/ 2020-OBSERVATORIO-BDSI-DOCEST-PRE-PANDEMIA-INFANCIA.pdf

5. Gupta RS, ShumanS, Taveras EM, Kulldorff M, Finkelstein JA. Opportunities for health promotion education in child care. Pediatrics. 2005; 116(4):e499-505.

6. Araujo MC, López-Boo F, Puyana JM. Overview of early childhood development services in Latin America and the Caribbean. Washington: Social protection and health Division, Inter-American Development Bank; 2013. [Accessed on: July 11 ${ }^{\text {th }}, 2021$ ]. Available at: https:// publications.iadb.org/bitstream/handle/11319/3617/ BID_Panorama_ESP $\% 20 \% 28 \mathrm{Web} \% 29$.pdf? sequence $=1$

7. Instrumento diagnóstico para centros de cuidado infantil y para hogares. Programa de Prevención en Salud para Centros de Cuidado Infantil. Fundasamin. [Accessed on: July $\left.22^{\text {nd }}, 2021\right]$. Available at: https: / / drive.google.com/ file/d/1NNPvi1TdmhrpDb3kuqr2CGxT3psTldKg/view

8. Araujo MC, Dormal M, Schady N. La calidad de losjardines de cuidado infantil y el desarrollo infantil. Documento de trabajo delBID n ${ }^{\circ}$ 779. Marzo 2017. [Accessed on:September $\left.29^{\text {th }}, 2021\right]$. Available at: https://publications.iadb.org/ publications / spanish / document / La-calidad-de-losjardines-de-cuidado-infantil-y-el-desarrollo-infantil. pdf

9. Marco Navarro F. Calidad del cuidado y la educación para la primera infancia en América Latina. Igualdad para hoy y mañana. CEPAL Política Sociales $N^{o} 204.2014$. [Accessed on: July $\left.20^{\text {th }}, 2021\right]$. Available at: https: / / repositorio.cepal. org/handle/11362/36822

10. Fiene R. 13 Indicators of quality child care: research update. Washington DC: Department of Health \& Human Services Home, Office of the Assistant Secretary for Planning and Evaluation; 2002. [Accessed on: July $20^{\text {th }}, 2021$ ]. Available at: https:/ / aspe.hhs.gov/ reports/13-indicators-qualitychild-care-research-update

11. Cao C (ed). The Role of the Child Care Health Advocate. San Fransisco, CA: California Childcare Health Program; 2006.

12. Child care health consultants: current models and implications for policy and practice. New York: NYS Early Childhood Advisory Council; 2013. [Accessed on: July $\left.20^{\text {th }}, 2021\right]$. Available at: http://www.nysecac.org/ application / files / 4415/5423 / 1088 / White_Paper_on Child_Care_Health_Consutlation_in_NYS_REVISED_ FINAL-Reformated_for_Posting.pdf

13. Alkon A, Bernzweig J, To K, Wolff M, Mackie JF. Child Care Health Consultation Improves Health and Safety Policies and Practices. Acad Pediatr. 2009; 9(5):366-70.

14. Ulione MS, Donovan E. Nursing in Project Head Start: Improving Health. Issues Compr Pediatr Nurs. 1996;19(4):22737.

15. Ramler M, Nakatsukasa-Ono W, Loe C, Harris K. The Influence of Child Care Health Consultants in Promoting Children's Health and Well-being: A Report on Selected Resources. Newton, MA: Education Development Center, Healthy Child Care Consultant Network Support Center; 2006. [Accessed on: July 20 $\left.0^{\text {th }}, 2021\right]$. Available at: https: / / www.mchlibrary.org/documents / 34010.pdf

16. Isbell P, Kotch J, Savage E, Gunn E. Improvement of child care programs' health and safety policies, and practices, and children's access to health care linked to child care health consultation. Dialog. 2013; 16(2):34-52.

17. Honigfeld L, Pascoe T, Macary S, Crowley A. Promoting Children's Health in Early Care and Education Settings by Supporting Health Consultation. Farmington, CT: Child Health and Development Institute of Connecticut. 2017. [Accessed on: July 20 $\left.0^{\text {th }}, 2021\right]$. Available at: https: / / www. chdi.org/index.php/download_file/view/1243/984/

18. Cloutier MM, Wiley JF, Trapp C, Haile J, Gorin AA. The Childcare Center: an Untapped Opportunity to Engage and Educate Families in Healthy Behaviors. J Racial Ethn Health Disparities. 2018; 5(2):430-8.

19. Rosenthal MS, Crowley AA, Curry L. Family Child Care Providers' Experience in Health Promotion. Fam Community Health. 2008; 3(4):326-34.

20. Rowe Minniss F, Wardrope C, Johnston D, Kendall E. Promoting Health in Early Childhood Environments: 
A Health-promotion Approach. Child Care Pract. 2013; 19(2):104-17.

21. Saville SK, Wetta-Hall R, Hawley SR, Molgaard CA, et al. An Assessment of a Pilot Asthma Education Program for Childcare Workers in a High-Prevalence County. Respir Care. 2008; 53(12):1691-6.

22. Krilov LR, Barone SR, Mandel FS, Cusack TM, et al. Impact of an infection control program in a specialized preschool. Am J Infect Control. 1996; 24(3):167-73.

23. Carabin H, Gyorkos TW, Soto JC, Joseph L, et al. Effectiveness of a training program in reducing infections in toddlers attending day care centers. Epidemiology. 1999; 10(3):219-27.

24. Amoah AO, Witherspoon NO, Pérodin J, Paulson JA. Findings from a pilot environmental health intervention at early childhood centers in the District of Columbia. J Public Health (Oxf). 2015; 38(3):e209-17.

25. Moon RY, Oden RP. Back to Sleep: Can We Influence Child Care Providers? Pediatrics. 2003; 112(4):878-82.

26. Ulione MS, Dooling M. Preschool injuries in child care centers: nursing strategies for prevention. J Pediatr Health Care. 1997; 11(3):111-6.

27. Johnston R, DelConte BA, Ungvary L, Fiene R, Aronson S. Child Care Health Consultation Improves Infant and
Toddler Care. J Pediatr Health Care. 2017; 31(6):684-94.

28. Doughty P.Contextual considerations for behavior change: Intervention/Method selection. In: Gilbert GG, Sawyer RG, McNeil EB. Health education. Creating strategies for school and community health. $3^{\text {rd }}$ ed. Boston: Jones and Bartlett Publishers; 2011.Pages 47-96.

29. Mistry KB, Minkovitz CS, Riley AW, Johnson SB, et al. A new framework for childhood health promotion: the role of policies and programs in building capacity and foundations of early childhood health. Am I Public Health. 2012; 102(9):1688-96.

30. Experiencias en Latinoamérica. In: Soria RM, Serra ME. Cuidado infantil de calidad: Un enfoque desde la salud. Buenos Aires: Fundasamin-Dunken; 2019.Pages 103-22.

31. Ultimate adult learning. In Edmunds C, Lowe K, Murray $\mathrm{M}$, Seymour A. The ultimateeducator: Achieving maximum adult learning through training and instruction. National Victim Assistance Academy Advanced Topic Series; 2002:3.1-14. [Accessed on: July 20 ${ }^{\text {th }}, 2021$ ]. Available at: https: / / www.ncjrs.gov/ovc_archives/educator/files / chapter3.pdf

32. Nebot M. Health promotion evaluation and the principle of prevention. J Epidemiol Community Health. 2006; 60(1):56. 


\begin{abstract}
ANNEX
Guideline for the final interview with participants of the "Training for referents of early childhood care centers in healthy care practices"
\end{abstract}

Name:

Care provider $\quad$ Educator $\quad$ Manager $\quad$ Other (Specify)

Child care center:

1- Question: What was the most interesting item of the training program for referents of early childhood care centers in healthy care practices?

Information to be collected: the interviewed participant should focus on one aspect: content, modality, group interaction, materials.

2- Question: In relation to your expectations before the training program, to what extent do you think they were met?

Information to be collected: to a lower extent, it met the expectations, it exceeded the expectations.

3- Question: How was the implementation of the improvement plan in your center? Did you get any help? With what aspects? Did you perceive resistance? When?

Information to be collected: to establish the extent of difficulty to implement the plan, whether any staff member overtly adhered to it or specifically resisted it, which hurdled the process in a specific moment.

4- Question: Is there any specific aspect that you believe benefited your center from your training and the plan implementation?

Information to be collected: to establish whether the participant recognizes or identifies any strength in the center's management, implementation or dynamics resulting from the training or plan implementation.

5- Question: Is there any aspect related to the center that you consider a problem or difficulty that needs to be resolved?

Information to be collected: assessment of problem relevance, knowing if the participant identifies any weakness in the management, implementation or dynamics of the center, establishing the relevance attributed to it and how the problem is measured, the position taken by the participant in relation to the problem, whether the participant considers the feasibility of working on it or simply dismisses it, and why.

6- Question: What challenges do you think lie ahead with the implementation in 6 months from now?

Information to be collected: adherence to the plan, new goals, and projected role. 